Article

\title{
Identification of Urban Functional Areas Based on POI Data: A Case Study of the Guangzhou Economic and Technological Development Zone
}

\author{
Yunfeng $\mathrm{Hu}{ }^{1, *(1)}$ and Yueqi Han ${ }^{1,2, *}$ \\ 1 Institute of Geographic Sciences and Natural Resources Research, Chinese Academy of Sciences, Beijing \\ 100101, China \\ 2 University of Chinese Academy of Sciences, Beijing 100049, China \\ * Correspondence: huyf@1reis.ac.cn (Y.H.); hanyq.16s@igsnrr.ac.cn (Y.H.)
}

Received: 17 December 2018; Accepted: 28 February 2019; Published: 6 March 2019

check for updates

\begin{abstract}
Functional areas are the basic spatial units in which cities or development zones implement urban plans and provide functions. Internet map big data technology provides a new method for the identification and spatial analysis of functional areas. Based on the POI (point of interest) data from AMap (a map application of AutoNavi) from 2017, this paper proposes an urban functional areas recognition and analysis method based on the frequency density and the ratio of POI function types. It takes the Guangzhou Economic and Technological Development Zone as a case study to analyze the main function and spatial distribution characteristics of the detailed functional areas. The research shows the following: (1) The POI frequency density index and the function type ratio can effectively distinguish the functions of the grid units and analyze the spatial distribution characteristics of a complex functional area. (2) The single functional area is the most common area type in the Guangzhou Economic and Technological Development Zone. The largest proportion of all areas is allocated to traditional manufacturing industry functional areas, followed by high-tech enterprises, catering and entertainment, real estate, and education and health care, in descending order. The smallest proportion is allocated to finance and insurance functional areas. (3) The current layout of the functional areas in the Guangzhou Economic and Technological Development Zone conforms to the overall requirements and planning objectives of the central and local government. The layout and agglomeration of different blocks within the economic development zone are consistent with local industry's target orientation and development history.
\end{abstract}

Keywords: point of interest; data mining; function identification; spatial distribution; regional planning

\section{Introduction}

The urban functional areas are geographic units composed of various interrelated elements within a city [1-3]. These elements are rationally arranged in space and are interconnected through various material, capital, and information flows to provide space for people's living, production, recreation, and business activities, providing a good living environment and forming an exchange platform $[4,5]$. Scientific, rational, and consistent functional zone planning are crucial to the implementation of long-term urban development goals. The rational layout and formation of urban functional areas can reduce the cost of urban housing purchases and living expenses, of residents' travel and commuting, and of production logistics. These characteristics will effectively enhance the pleasure of urban living, reduce the cost of urban large-scale production, improve the quality and efficiency of urban material and cultural production, attract more farmers and other residents of small towns to live in the city, 
and increase the city's competitiveness at the national and international levels $[6,7]$. The identification of urban functional areas is an important basis for judging whether urban and rural planning and construction goals are achieved during the process of construction, and it is also the starting point for future urban development planning work. With their important role of attracting foreign investment, increasing employment, and fostering export and economic growth, development zones have played a strong supporting role in promoting regional economic development [8-11]. The first batch of national economic and technological development zones was built in 1984, and as of September 2015, 219 national economic and technological development zones had been established throughout China, covering all provinces, municipalities, and autonomous regions [12]. By identifying and analyzing the urban functions of the development zones, we can compare their target orientation with the actual construction results, then evaluate the progress and effectiveness of their planning and construction, and, finally, appraise the performance of the relevant personnel in charge.

The early methods for identifying and dividing regions or urban functional areas were most often based on qualitative methods, such as breaking point theory and the field strength method [13]. After the 1960s, given the development and maturity of geographic metrology, the method of functional area identification and division has gradually become quantitative [14]. Wang Fa et al. selected 16 indicators that influenced the central intensity of the city, such as population size and natural obstacles, and then calculated the urban centrality intensity of Henan Province using a multivariate statistical method and delineated the urban circle in Henan Province [15]. Willam Mitchell introduced the hierarchical clustering algorithm into functional area identification to divide the Sydney commuter area. The resulting district divisions enhanced the understanding of the operating rules of Sydney's labor market [16]. Wang Bihui et al. proposed a city remote sensing image classification system to guide the manual interpretation of high-resolution images, and extracted high-precision urban elements in Beijing using this system [17]. Based on the object-oriented classification method, Wang Caiyan et al. completed the automatic extraction of urban land use in Beijing [18]. In general, although functional area identification based on economic statistics is a simple and effective method, it is difficult for economic geographers to obtain the statistical data that the method needs. In addition, it is difficult to determine whether the threshold is reasonable in the process of functional area identification and division. Although land use interpretation by remote sensing technology provides another method for identifying and classifying functional areas, land use classification is only an indirect indicator for characterizing urban functional areas. At the same time, there are still problems with remote sensing methods, such as time-consuming and laborious manual interpretation and the inaccurate identification by machine-aided automatic interpretation methods [19].

In recent years, geoscience big data based on Internet spatiotemporal mega data has brought new ideas and methods, helping us to understand and quantitatively analyze the spatial and temporal pattern characteristics of complex natural regions and socioeconomic systems [20-25]. For example, point of interest (POI) data provide a fast and effective alternative to the division of urban functional areas [24,26-29]. POI data include all geographic entities that can be abstracted as points, such as schools, banks, companies, restaurants, and supermarkets [30-34]. POI data record the spatial and attribute information of geographic entities, including name, address, coordinates, type, and evaluation of the entity. They have the advantage of detailed information coverage, huge data volume, and convenient access to quantitative analyses. In related works, many researchers have studied urban spatial patterns based on POI data. Based on POI data, Xu Zening et al. proposed the DensiGraph analysis method to identify the boundaries of urban built-up areas [35]. Chi Jiao and Kang Yuhao et al. used POI data to identity functional zones in Wuhan City with the quadrate density method [36,37]. Based on Beijing logistics POI data, Li Guoqi et al. used industrial concentration evaluation and nuclear density analysis methods to describe the spatial pattern of Beijing logistics [38]. Yuan Jing et al. used Beijing taxi trajectory data to characterize population flow with the assistance of POI data. They proposed a framework named DRoF that discovers regions with different functions to identify Beijing's functional areas [39]. Previous studies illustrate that we can identify and zone the urban and rural borders, logistics patterns, or urban functional areas by using POI data $[40,41]$. 
However, these methods also have some problems. For example, the calculation model was too complex, the scale of research was too large, and the analyses of the mechanism behind the development of functional areas was still insufficient and needs in-depth study [42].

In summary, the morphology of a city affects its ecological and socioeconomic functions, and thus, how a city is spatially structured has an important bearing on urban sustainability [43]. A reasonable distribution of urban functional areas can improve the efficiency of urban land use and promote sustainable urban development [44]. The availability of big data provides great potential for identifying and mapping urban functional zones [45]. The advantages of POI data, such as a large amount of data, easy access, and detailed information, offer a new perspective for urban functional zone identification methods. To solve the problems in the existing urban functional zone identification methods based on POI data, we applied a method for functional area identification based on POI data that is simple, effective, and can be used in complex areas in the Guangzhou Economic and Technological Development Zone. We also conduct a detailed analysis of the main functions and spatial distribution rules for various functional combinations in the Guangzhou Economic and Technological Development Zone. The main issues that we focused on are as follows:

1. How can the spatial distribution of urban functional areas based on POI data be quickly and effectively identified?

2. What is the spatial distribution of the functional zones in the Guangzhou Economic and Technological Development Zone?

3. Does the current functional zone distribution of the Guangzhou Economic and Technological Development Zone conform to the central and local government planning objectives?

\section{Materials and Methods}

\subsection{Study Area}

The Guangzhou Economic and Technological Development Zone was established in 1984 with the approval of the State Council. It was one of the first national economic and technological development zones in China. The total area of Guangzhou Economic and Technological Development Zone is about $33.35 \mathrm{~km}^{2}$, with its GDP (Gross Domestic Product) reaching 320.953 billion yuan in 2017. The specific location and scope of the study area are shown in Figure 1. The districts are Yonghe District, Eastern District, and Western District, from top to bottom in the right of Figure 1, with an area of $11.45 \mathrm{~km}^{2}, 16.53 \mathrm{~km}^{2}$, and $5.37 \mathrm{~km}^{2}$, respectively.

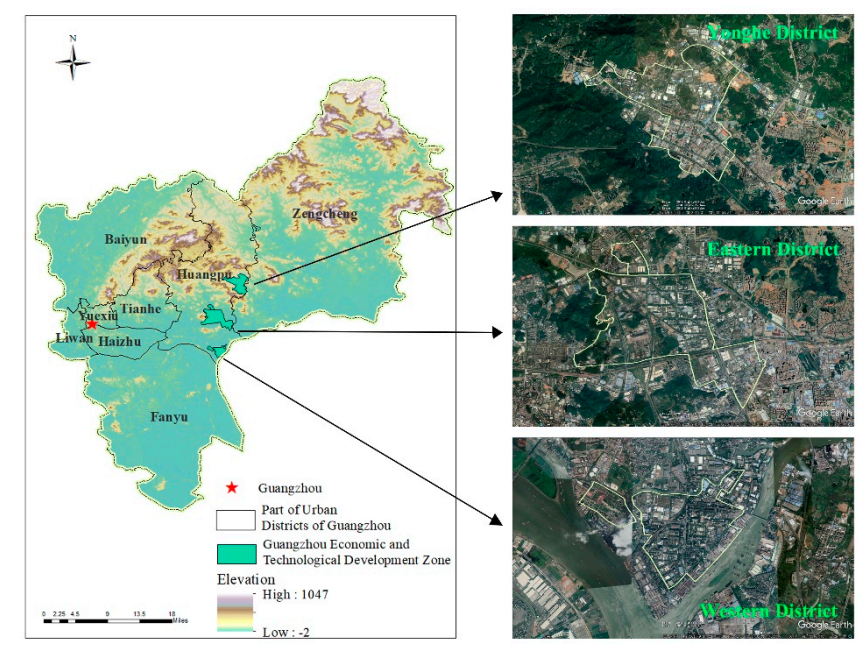

Figure 1. The Location and Boundaries of Research Zones. The administrative division data are from the 1:250,000 basic geographic database provided the National Geomatics Center of China, the DEM data are SRTM30_1 km DEM data (http:/ / files.ntsg.umt.edu/data/SRTM30_1km/), and the remote sensing image data are from Google Earth (https:/ / earth.google.com/web/). 


\subsection{Data and Preprocessing}

In this paper, more than 128,000 POIs for Guangzhou City were obtained from AMap in 2017 [46], of which 27,192 were within the Guangzhou Economic and Technological Development Zone. Attributes of POI data include 12 fields, such as POI name, type, type code, contact mode, longitude, latitude, address, city, county, street, postal code, and door number. POI data are divided into 20 categories based on their business services. Considering the specific needs of urban planning, this paper reclasses the above 20 categories of POI into 6 categories: high-tech enterprises, traditional manufacturing industry, real estate, catering and entertainment, education and health care, finance, and insurance. The correspondence in the reclassification process is shown in Table 1.

Table 1. Classification System of POI Data.

\begin{tabular}{ll}
\hline Classification System of AMap & Classification System of This Paper \\
\hline $\begin{array}{l}\text { Enterprises focus on science, new technology, information, } \\
\text { medical, network and electronic }\end{array}$ & High-tech enterprises (High-tech) \\
\hline Enterprises except high-tech enterprises & Traditional manufacturing industry (Industry) \\
\hline Commercial real estate & Real estate (Estate) \\
\hline $\begin{array}{l}\text { Catering services, shopping services, sports and leisure } \\
\text { services, accommodation services, scenic spots }\end{array}$ & Catering and entertainment (C\&E) \\
\hline $\begin{array}{l}\text { Scientific and Educational Cultural Services, Medical and } \\
\text { Health Care Services }\end{array}$ & Education and health care (E\&H) \\
\hline $\begin{array}{l}\text { Finance and insurance services } \\
\begin{array}{l}\text { Automobile services, car sales, car maintenance, motorcycle } \\
\text { services, life services, government agencies and social } \\
\text { organizations, transportation facilities services }\end{array}\end{array}$ & Finance and insurance (F\&I) \\
\hline
\end{tabular}

The classification system in AMap is from the webservice site of AMap (https:/ /lbs.amap.com/api/webservice/download).

\subsection{Identification Framework}

The process of urban functional area identification based on POI data is shown in Figure 2. Based on POI data reclassification, we eliminate the POIs outside the study area according to the scope of the study area. After repeat experiments, we chose a $250 \mathrm{~m}$ grid as a basic unit. Then, the POI data are superimposed on the $250 \mathrm{~m}$ fishnet data of the development zone, and the number of POIs of various types in each grid was counted.

To identify the main function of each $250 \mathrm{~m}$ grid unit, we construct two indicator indexes, the frequency density index $\left(F_{i}\right)$ and the ratio index $\left(C_{i}\right)$, to judge the type of functional area. The formula is as follows:

$$
\begin{gathered}
F_{i}=\frac{n_{i}}{N_{i}} \quad(i=1,2, \ldots, 6) \\
C_{i}=\frac{F_{i}}{\sum_{i=1}^{6} F_{i}} \times 100 \%(i=1,2, \ldots, 6)
\end{gathered}
$$

In the formula, $i$ is the POI type, $n_{i}$ is the number of type $i$ POIs in a grid unit, $N_{i}$ is the total number of type $i$ POIs, $F_{i}$ is the frequency density of type $i$ POIs in a grid unit, and $C_{i}$ is the proportion of the frequency density of type $i$ POIs in a grid unit.

After calculating $F_{i}$ and $C_{i}$ of every grid unit, the function discriminant analysis can be performed. When $C_{i}$ of one type in a grid unit is more than $50 \%$, this unit can be seen as a single functional area, and the type of this unit is the same as $i$ of maximum $C_{i}$. When all $C_{i}$ are less than $50 \%$, this unit can be seen as a mixed functional area, and the types of this unit are determined by the $i$ of the top three $C_{i}$. When any POI is not included in a grid unit, that is, when $C_{i}$ is null in this unit, the unit is seen as no data area. 


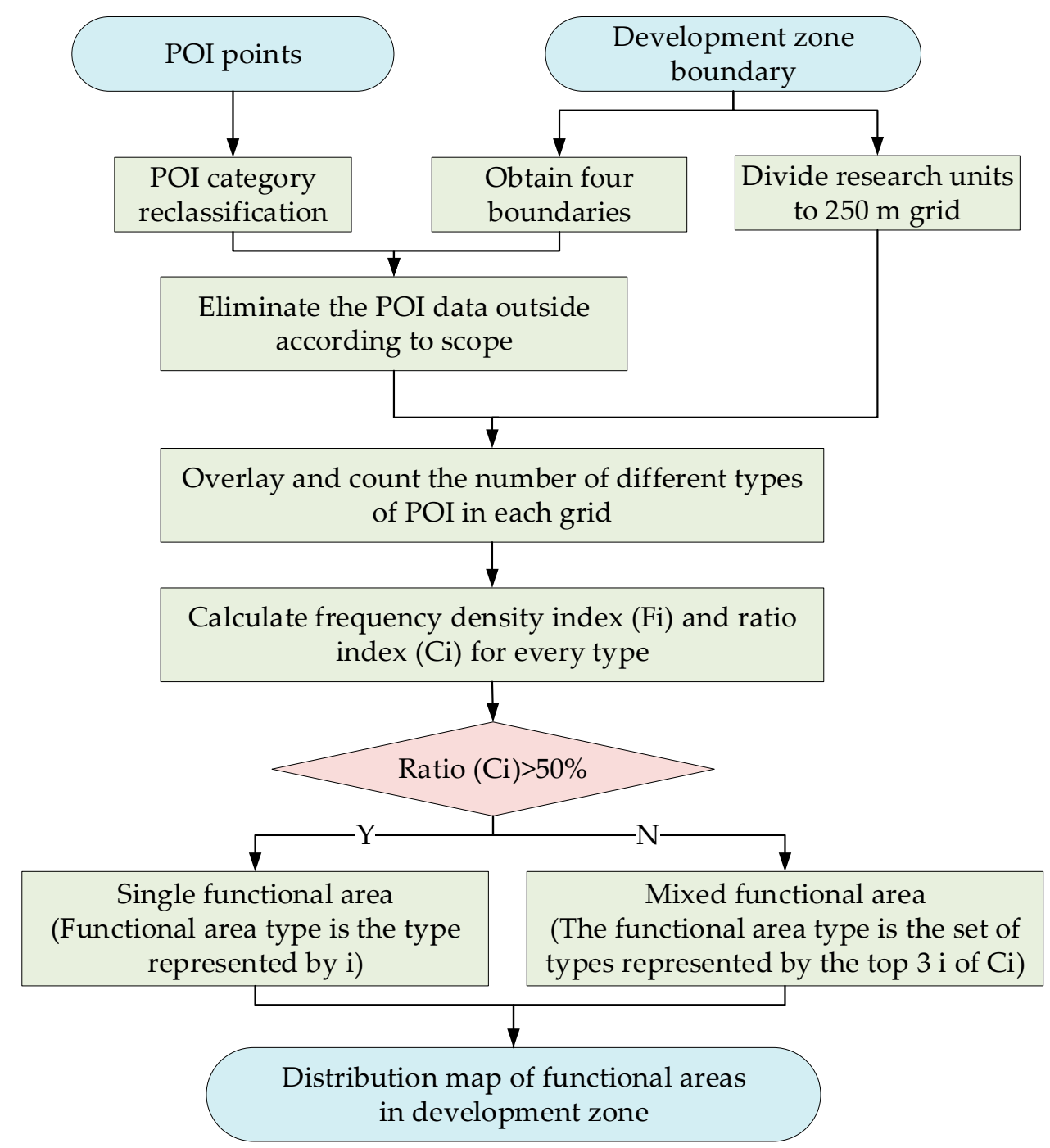

Figure 2. The Process Flow of Functional Area Identification Based on POI Data.The figure shows the process of functional area identification based on POI data, including data preprocessing and functional area identification with 2 indicators.

\section{Results}

\subsection{Functional Areas in Whole Development Zone}

The Guangzhou Economic Development Zone takes the single functional areas as its main layout form as a whole (Figure 3). Specifically, on the $250 \mathrm{~m}$ scale, single functional areas account for $52.46 \%$ of the total area of the development zone, mixed functional areas account for $17.07 \%$, and no data areas account for $30.46 \%$. Spatially, the Yonghe District and the Eastern District are dominated by single functional areas, while the Western Region is characterized by single functional areas and mixed functional areas, with the mixed function areas being slightly larger than the single functional areas.

Figure 4 shows the proportions of all types. In terms of single functional areas, the traditional manufacturing industry type has the largest proportion, accounting for $26.34 \%$ of all single functional areas, followed by the high-tech enterprises type, which accounts for $9.53 \%$. There are two reasons for the dominance of the traditional manufacturing industry and high-tech enterprise functional areas. One is that companies or enterprises are numerous, and the other is that every company or enterprise occupies a large area. Then, the next largest proportion is devoted to catering and entertainment, real estate, and education and health care functional areas, while the proportion of the finance and insurance functional area is smallest. From the perspective of spatial distribution, 
traditional manufacturing industry and high-tech enterprise functional areas are concentrated in Yonghe District and Eastern District but are sparse in the Western District. Other types of areas are scattered throughout the development zone.

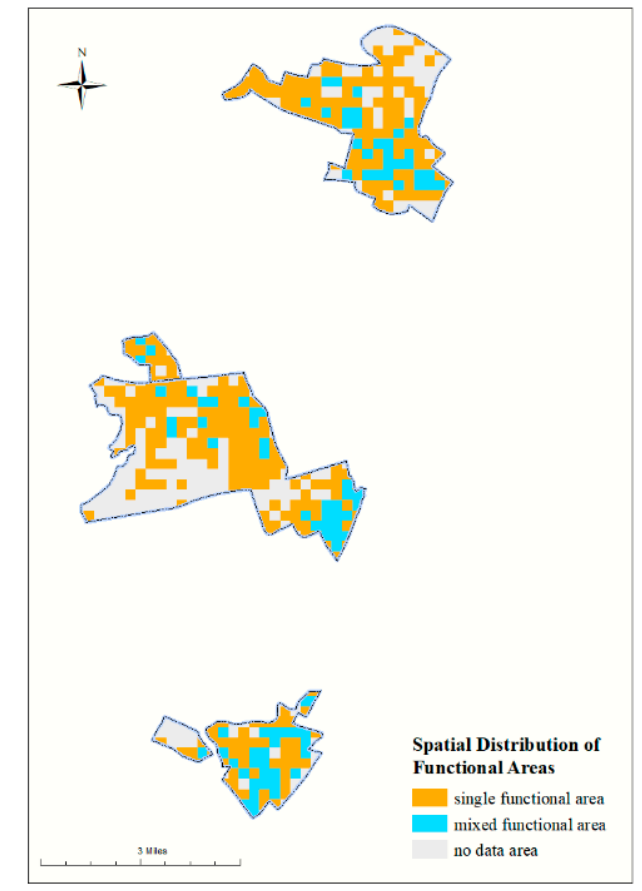

(a)

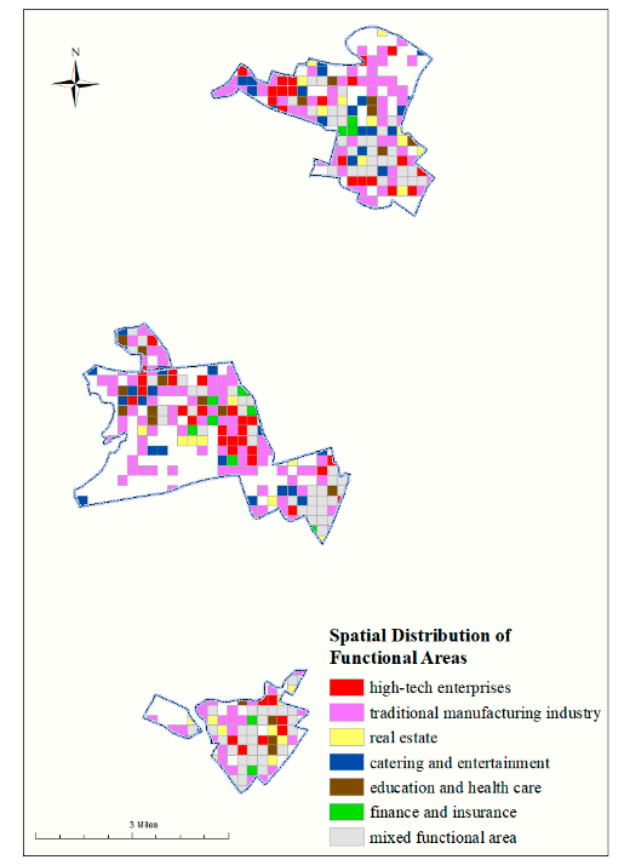

(b)

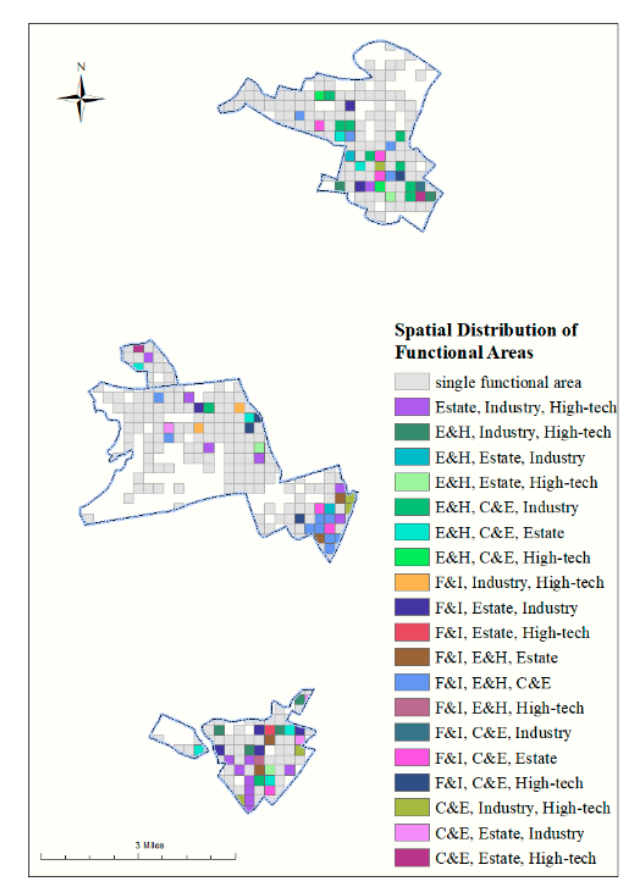

(c)

Figure 3. Spatial Distribution of Functional Areas in the Guangzhou Economic and Technical Development Zone: (a) Distribution of Single/Mixed Functional Areas. (b) Distribution of Single Functional Areas. (c) Distribution of Mixed Functional Areas. On a $250 \mathrm{~m}$ scale, single functional areas account for $52.46 \%$ of the total area of the development zone, while mixed functional areas account for $17.07 \%$. 


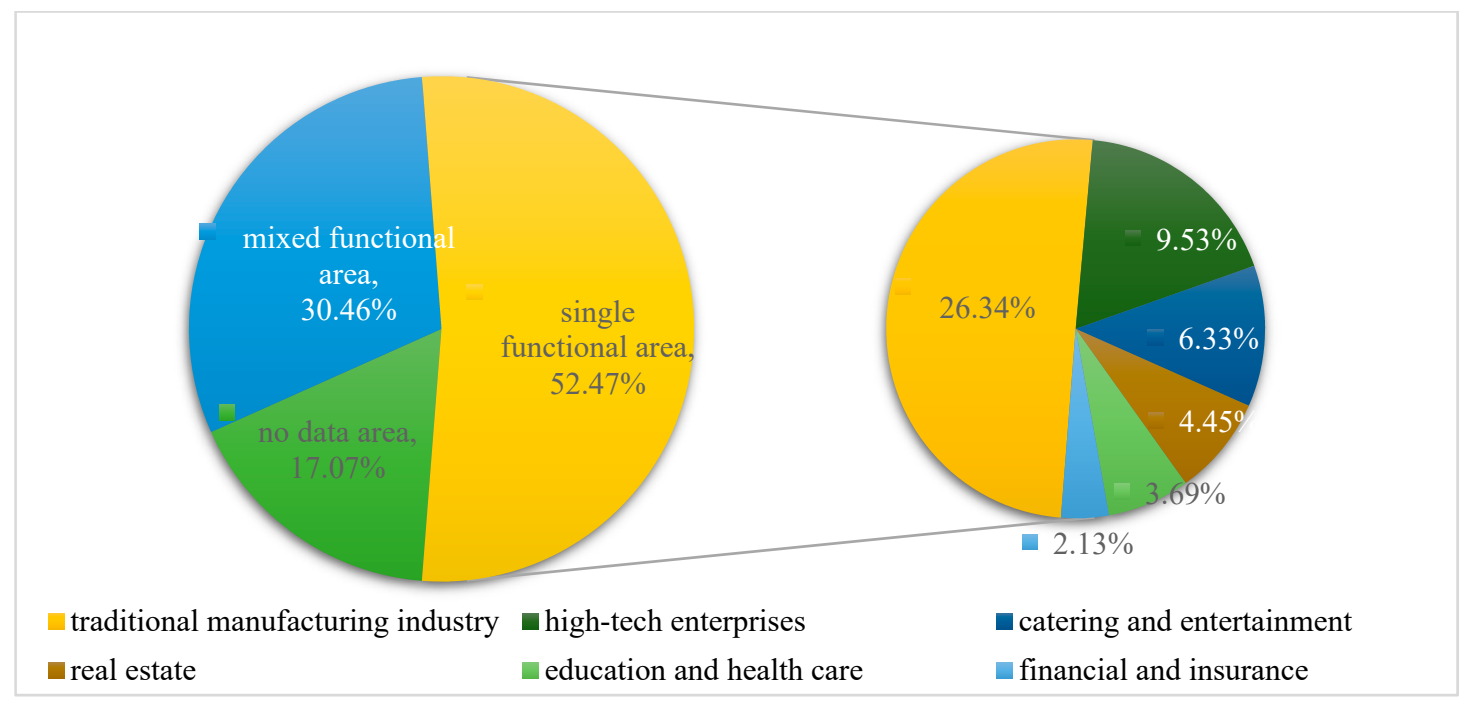

(a)

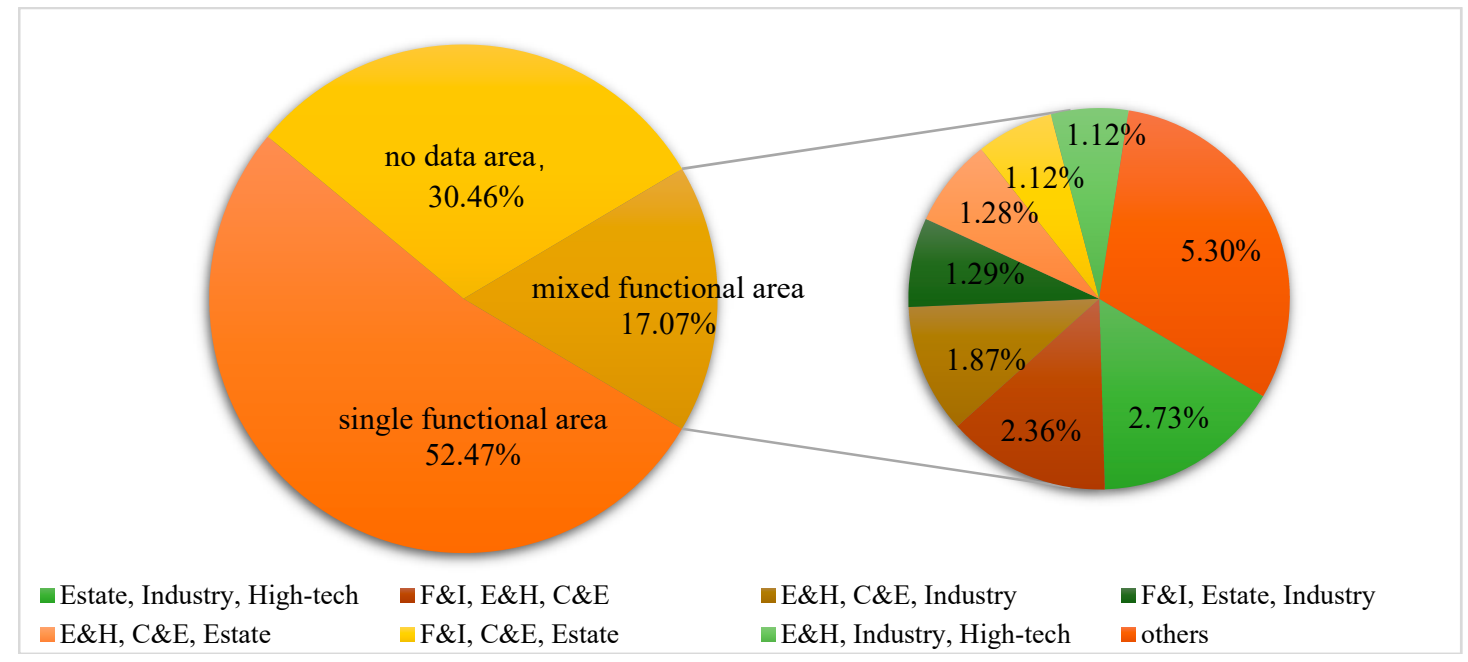

(b)

Figure 4. Proportion of All Types: (a) Proportion of Single Functional Areas. (b) Proportion of Mixed Functional Areas. For single functional areas, the traditional manufacturing industry type represents the largest proportion, accounting for $26.34 \%$, while for mixed functional areas, the combination of real estate, traditional manufacturing, and high-tech enterprises represents the largest proportion, at $2.73 \%$.

For the mixed functional areas, the combination of real estate, traditional manufacturing, and high-tech enterprises account for the largest proportion, at $2.73 \%$ of all mixed functional areas, followed by the combination of finance and insurance, education and health care, and catering and entertainment, which accounts for $2.36 \%$. Considering the spatial distribution, the mixed functional areas are mainly distributed in the south of Yonghe District, the south of the Eastern District, and the majority of the Western District. The mixed functional areas of real estate, traditional manufacturing, and high-tech enterprises are mainly distributed in the south of the Western District, while the mixed functional areas of finance and insurance, education and health care, and catering and entertainment are mainly distributed in the southwest of the Eastern District.

\subsection{Functional Areas in Every District}

The spatial distribution of functional areas in Yonghe District is shown in Figure 5. In Yonghe District, single functional areas represent a larger proportion, accounting for $60.98 \%$, while mixed functional areas account for $12.70 \%$. The proportion of single functional areas in the Yonghe District 
is higher than that in the whole development zone, which reflects the centralized and compact distribution of POIs of the same type in that district. From the perspective of the spatial distribution of the single functional area, Yonghe District is mainly dominated by traditional manufacturing industry areas, accounting for $27.78 \%$ of the total Yonghe District, mainly concentrated in the northeast and west of Yonghe. The second type is high-tech enterprises, accounting for $10.53 \%$, mainly distributed in the west and south of Yonghe. Then, the proportion of catering and entertainment areas, real estate areas, and education and health care areas decrease in turn. Finance and insurance functional areas have the least grid units. In terms of the spatial distribution of mixed functional areas, the combination of education and health care, and catering and entertainment with traditional manufacturing industry or high-tech enterprises occupies the most grid units. These units are staggered with single function areas in the southern Yonghe District.

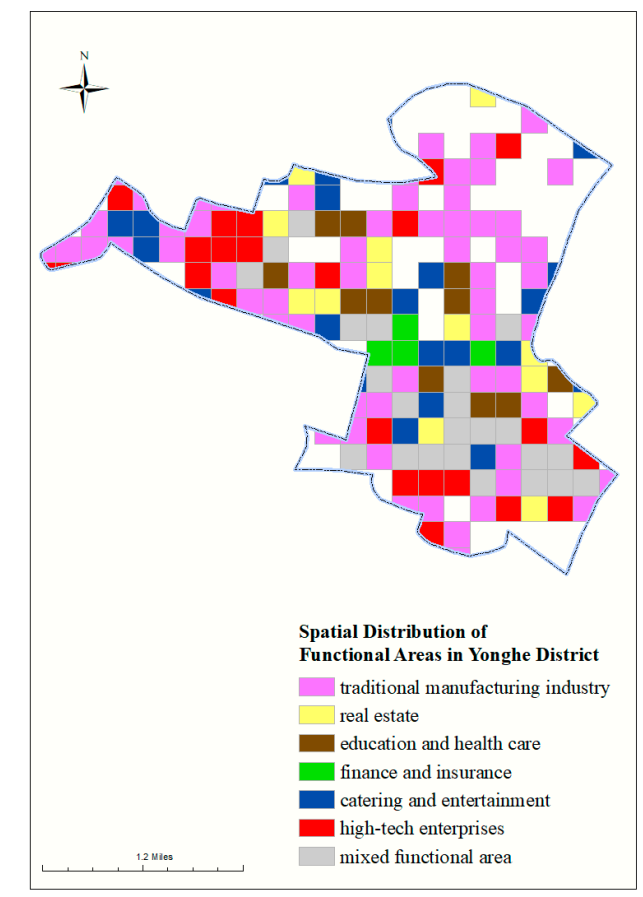

(a)

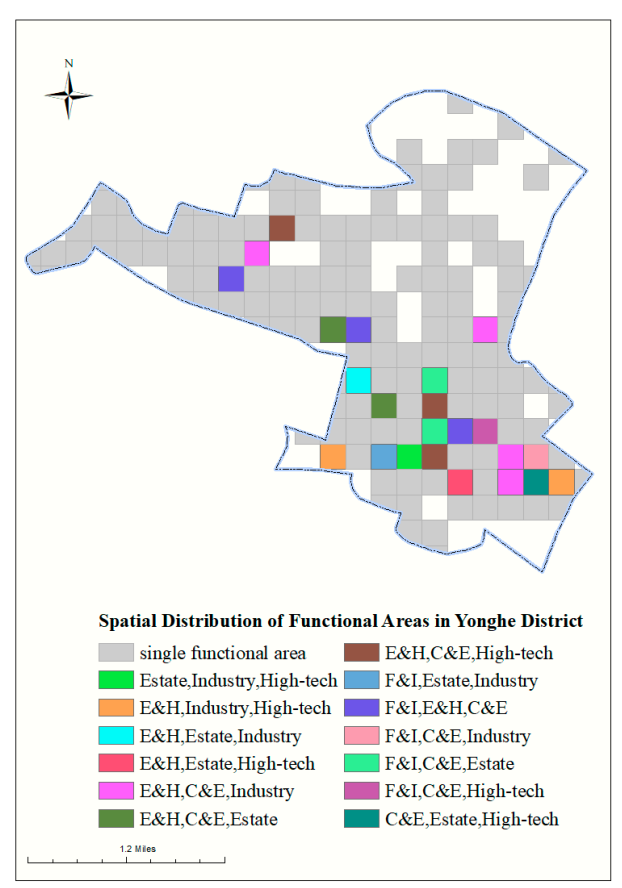

(b)

Figure 5. Spatial Distribution of Functional Areas in Yonghe District: (a) Distribution of Single Functional Areas. (b) Distribution of Mixed Functional Areas. In Yonghe District, the total area devoted to single functions is larger than that for mixed functions. For the single functional areas, Yonghe District is mainly dominated by traditional manufacturing industry areas, while for the mixed functional areas, the combination of education and health care and catering and entertainment with traditional manufacturing industry or high-tech enterprises occupies the most grid units.

The spatial distribution of functional areas in the Eastern District is shown in Figure 6. In the Eastern District, the single functional areas have a larger proportion, accounting for $51.14 \%$, while the mixed functional areas account for only $12.39 \%$. From the perspective of the spatial distribution of the single functional areas, the Eastern District is dominated by the traditional manufacturing industry areas, accounting for $26.44 \%$ of the total Eastern District, evenly distributed throughout the Eastern District. The second type is high-tech enterprises, accounting for $9.38 \%$, which are mainly distributed in the eastern fringe of the Eastern District. Then, the proportion of catering and entertainment areas, education and health care areas, and real estate areas decreases in turn. Finance and insurance functional areas have the least grid units. In terms of the spatial distribution of mixed functional areas, the combination including finance and insurance occupies most grid units, containing various 
investment companies and commercial bank outlets, and is mainly distributed along Pioneer Avenue in the north and in the Southeast corner of the Eastern District.

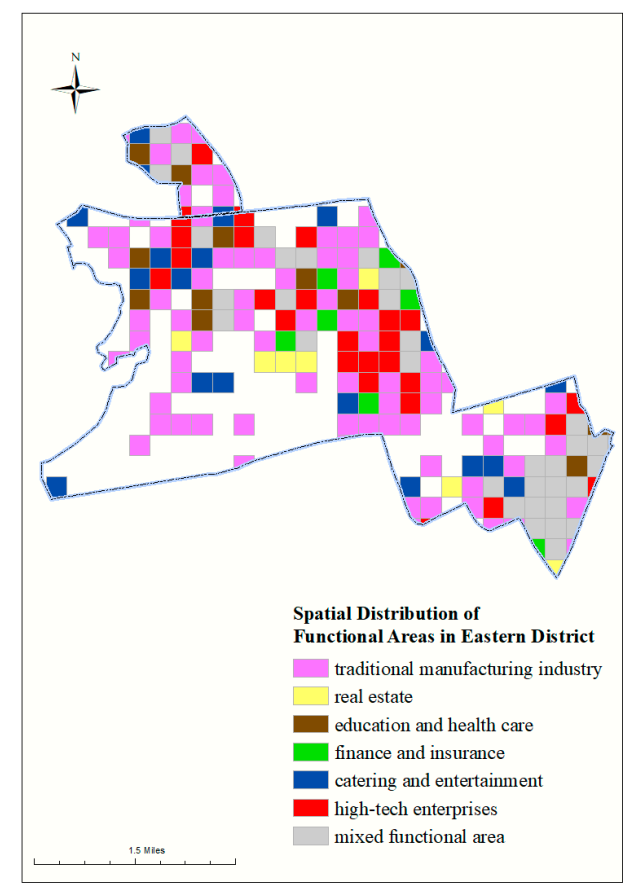

(a)

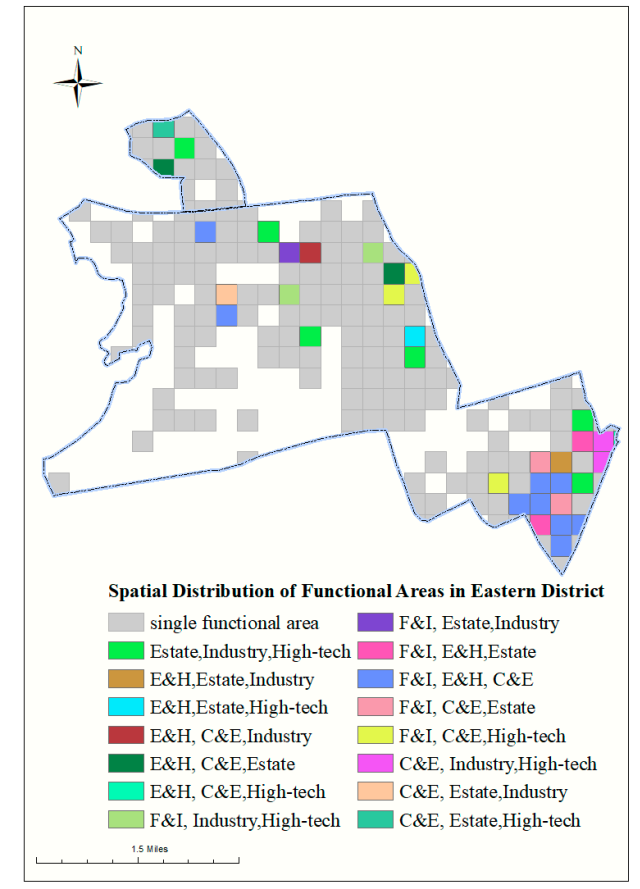

(b)

Figure 6. Spatial Distribution of Functional Areas in Eastern District: (a) Distribution of Single Functional Areas. (b) Distribution of Mixed Functional Areas. In the Eastern District, the total area devoted to single functions is larger than that for mixed functions. For the single functional areas, the Eastern District is mainly dominated by traditional manufacturing industry areas, while for the mixed functional areas, the combination including finance and insurance occupies most grid units.

The spatial distribution of functional areas in the Western District is shown in Figure 7. In the Western District, the total area of single functional areas accounted for $47.14 \%$, which is smaller than the proportion of single functional areas in the Yonghe District and Eastern District, while the total area of mixed functional areas accounted for $32.87 \%$, which is significantly larger than the other two districts. From the perspective of the spatial distribution of the single functional area, the Western District is mainly dominated by traditional manufacturing industry areas, accounting for $23.44 \%$ of the total Western District, which are evenly distributed throughout the Western District. The second type is real estate, accounting for $8.44 \%$, which is mainly distributed at the edge of the Western District. Then, the proportion of high-tech enterprises areas, education and health care areas, and finance and insurance areas decrease in turn. The catering and entertainment functional areas have the least grid units. In terms of the spatial distribution of mixed functional areas, the combination of real estate, high-tech enterprises, and traditional manufacturing industry occupies most grid units, accounting for $9.10 \%$, which are mainly concentrated in the center of Western District. The second is the combination of education and health care, traditional manufacturing industry, and high-tech enterprises, accounting for $4.78 \%$, mainly distributed in the north of the Western District. 


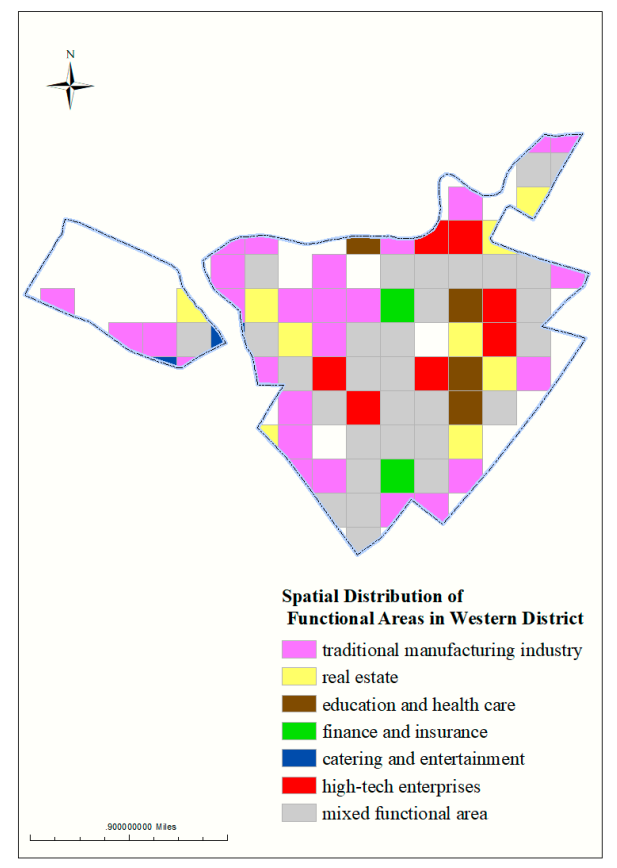

(a)

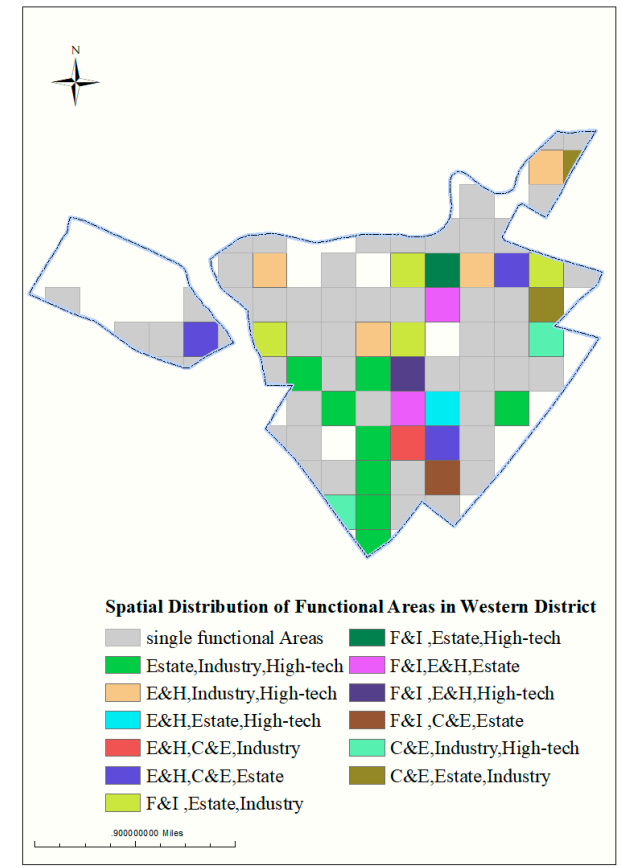

(b)

Figure 7. Spatial Distribution of Functional Areas in the Western District: (a) Distribution of Single Functional Areas. (b) Distribution of Mixed Functional Areas. In the Western District, the total area devoted to single functions is larger than that for mixed functions. For single functional areas, the Western District is mainly dominated by traditional manufacturing industry areas, while for the mixed functional areas, the combination of real estate, high-tech enterprises, and traditional manufacturing industry occupies most grid units.

\section{Discussion}

\subsection{Comparative Analysis}

To verify the feasibility of the functional area identification method used in this article, we selected one grid unit in each type of functional area as the sample according to the results from the single functional area identification in the Eastern District of the Guangzhou Economic and Technological Development Zone. Then, we visually interpreted the Google Earth satellite images of all of the sample units and compared the functional area identification results based on POI data with the visual interpretation results. The comparison is shown in Figure 8. The sample units containing traditional manufacturing industry and high-tech enterprise functional areas are shown as large factories, the sample unit containing education and health care functional area is shown as playgrounds, and the sample unit containing real estate functional area is shown as a residential area. The entities within the catering and entertainment or finance and insurance function types occupy a small area and are mostly mixed with other entities. The land use characteristics of these entities are not significant, so it is hard to distinguish them in the image. However, in the electronic map, we can see that restaurants and shops are the main entities in the catering and entertainment sample unit, while banks, ATM machines, and insurance companies are the main entities in the finance and insurance sample unit.

By comparing functional area identification results with satellite images or electronic maps, it can be seen that the spatial distribution of different functional areas in the Guangzhou Economic and Technological Development Zone can be effectively identified by POI-based methods if we do not consider errors in the original POI data. 

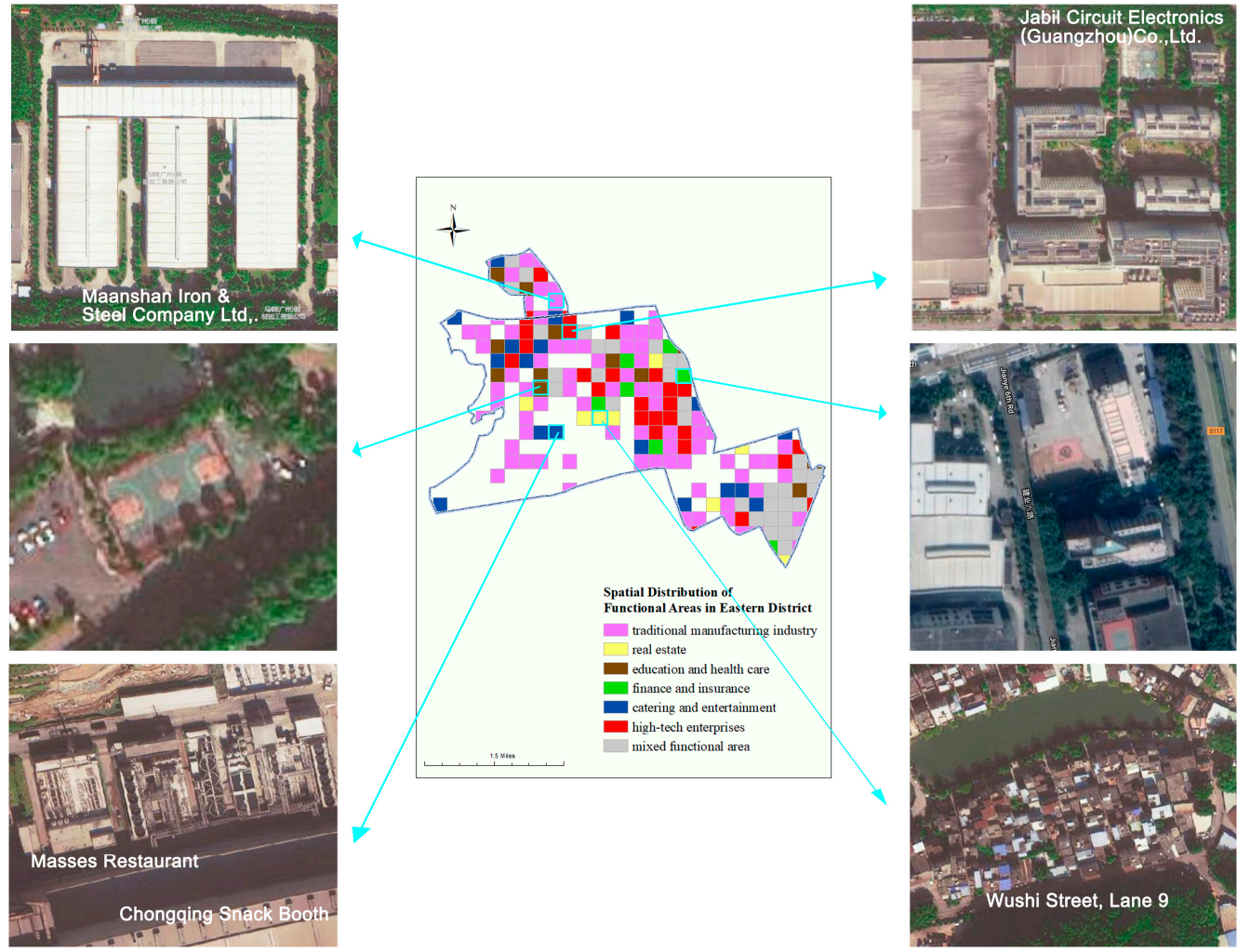

Figure 8. A comparison of the functional area identification results based on POI data with the visual interpretation results for the sample units. The spatial distribution of different functional areas in the Guangzhou Economic and Technological Development Zone can be effectively obtained by the POI-based identification method.

\subsection{Development Process and Industry Layout in Guangzhou Economic and Technological Development Zone}

The State Council established the following aims for economic and technological development zones: "to develop industries, to utilize foreign capital, to earn foreign exchange through exports, and to devote themselves to the development of high-tech industries" [47]. Since its establishment in 1984, the Guangzhou Economic and Technological Development Zone has actively introduced foreign capital, advanced technology and management experience, and vigorously developed the processing manufacturing industry and high-tech industries [48-50]. Since 2014, given the profound changes in the global economic and industrial structure, China's economic development has transitioned into "The New Normal". Faced with this new context, the State Council has proposed "optimizing the shape and layout of development zones, and speeding up the transformation and upgrading of development zones" [51]. The Guangzhou Economic and Technological Development Zone actively responded to the aims of the State Council by adjusting its industrial structure, changing its development mode, and optimizing its industrial space layout.

Examining the results for the urban functional areas identified using POI data from the Internet map, an analysis of the various functional areas and the characteristics of their overall area proportion a the $250 \mathrm{~m}$ scale show that the Guangzhou Economic Development Zone has indeed formed a general pattern of functional construction with the traditional manufacturing industry and high-tech enterprises as the main functional areas supported by real estate, catering and entertainment, education and health care, and finance and insurance. This pattern is consistent with the general requirements and specific planning objectives of the central and Guangdong provincial governments for economic development zones. The instructions from the central government to the Guangzhou Economic and Technological Development Zone for the construction of economic development zones 
have been followed, and the actual construction results conform to the planning documents and development goals.

Furthermore, the monitoring results based on POI data from Internet maps are consistent with the data from statistical channels. The statistical yearbook of development zones shows that in 2017, the GDP of the Guangzhou Development Zone reached 320.953 billion yuan. The benefits of traditional pillar industries were stable, and the gross output value of industries above the scale reached 745.911 billion yuan. The high-tech industry has seen significant improvement as a driving force in economic development. The total number of high-tech enterprises identified has reached 1632, and the output value of high-tech industrial enterprises above the region's scale has reached 170.422 billion yuan. The development zone now forms a modern service agglomeration area including a business district, economic zone headquarters, and financial innovation service zone.

Considering the spatial distribution details for the functional areas of the three major districts-Yonghe District, Eastern District, and Western District-in the development zone, the three districts have formed their own unique layout characteristics given their different development histories and locations. The West District was the earliest construction in the Guangzhou Economic and Technological Development Zone. In 2015, the Guangzhou Economic and Technological Development Zone proposed promoting the transformation of the Western District from an old industrial zone to a modern science and technology city integrating industry, residential space, and modern service industries. Since that time, the West District has carried out large-scale industrial upgrading and public infrastructure construction, and it is expected that the proportion of mixed function areas in the West District will further increase in the future. The Eastern District has been striving to build an industrial upgrading base in Guangzhou since 1992. Therefore, the industrial structure of the Eastern District is mainly composed of light industries, such as the chemical industry, food and beverage manufacturing, and electronic communication equipment manufacturing, and heavy industries, such as transportation equipment manufacturing. In April 2000, the Guangzhou Export Processing Zone was established in the Eastern District, with automobile manufacturing as the main industry. The above industrial development goals and the characteristics of the enterprise scale contribute to the formation of single functional areas. The Yonghe District is the most recent, founded in 1993 mainly as a gathering area for Taiwanese investment. It is the main gathering area of the advanced processing industry in the Guangzhou Economic and Technological Development Zone. The overall positioning of this industrial park and its goal of attracting investment contribute to the formation of single functional areas, and it is easier to form high-tech industrial chain enterprises. The results of the POI-based functional area identification shows that Yonghe District is indeed dominated by manufacturing and high-tech enterprises.

\section{Conclusions}

To identify functional areas within the development zone based on POI data, this paper conducts spatial identification of the functional areas of the Guangzhou Economic and Technological Development Zone and analyzes and discusses the spatial distribution and spatial aggregation characteristics of the detailed functional areas within the three districts of the Guangzhou Economic and Technological Development Zone. The main conclusions are as follows:

1. POI data provided by Internet maps are free, easily obtained, and have the advantage of large volumes and more detail. These advantages mean that POI data offer a new perspective for urban functional area identification methods. Constructing the POI frequency density and function type proportion index model allows for the rapid and effective identification of urban functional areas.

2. In the Guangzhou Economic and Technological Development Zone, on a $250 \mathrm{~m}$ scale, the area devoted to single functions is greater than that given to mixed functions. The traditional manufacturing industry functional areas hold the largest proportion, followed by high-tech enterprises areas, catering and entertainment areas, real estate areas, and education and health care areas. The finance and insurance areas account for the smallest proportion. Among the 
mixed functional areas, the mixed areas with real estate, traditional manufacturing industry, and high-tech enterprises account for the largest proportion.

3. The Guangzhou Economic Development Zone has indeed constructed development goals following the general pattern of traditional manufacturing and high-tech enterprises as the main functional areas, and real estate, catering and entertainment, education and medical treatment, and finance and insurance as supporting facilities. Based on a historical analysis of the development of the economic development zone, it can be seen that the current development and functional layout of the Guangzhou Economic Development Zone conforms to the general requirements and planning objectives of the Central Committee and Guangdong Province. Within the economic development zone, the layout and clustering characteristics of functional areas in different plots agree well with the industrial development goals, construction planning, and development history of the region.

This research provides a method for urban functional area identification based on POI data from the Internet map and carries out a case application for the Guangzhou Economic Development Zone. The results indicate that this method using POI data has high potential for application to the analysis of spatial distribution characteristics of urban functional areas and urban functional allocation planning. It should be noted that although the POI method has the above advantages, in its future applications, we still need to consider the uncertainty and incompleteness of POI data from the Internet map. In particular, when POI data are mainly collected through crowdsourcing, the above problems will become more prominent. In addition, in the process of urban functional area analysis, the scale should be considered in the grid division of urban functional areas. The size of the cell grids may have a slight impact on the conclusions of the study. An important future research direction is to recognize and divide functional areas with adaptive scales by combining traffic road data and the multiscale segmentation method from remote sensing images.

Author Contributions: Y.H. (Yunfeng Hu) designed the idea and methodology. Y.H. (Yueqi Han) implemented the idea, performed the experiments, and preliminarily analyzed the results. All authors drafted and revised the paper.

Funding: This research was funded by Strategic Priority Research Program of Chinese Academy of Sciences (grant number XDA23100201, XDA20010202, XDA19040301), National Key Research and Development Plan Program in China (grant number 2016YFC0503701, 2016YFB0501502), and Key Project of High Resolution Earth Observation System in China (grant number 00-Y30B14-9001-14/16).

Conflicts of Interest: The authors declare no conflict of interest.

\section{References}

1. Liu, X.; Peng, W. Urban functional zoning and zoning classification management. Urban Oper. Manag. 2010, 4, 20-22.

2. Gu, C.; Wang, Y.; Shao, Y.; Gu, J. Research on administrative divisions based on functional areas analysis: A case of shaoxing metropolitan area. Acta Geogr. Sin. 2015, 70, 1187-1201.

3. Zhang, X.; Hua, Q.; Zhang, L. Development and application of a planning support system for regional spatial functional zoning based on gis. Sustainability 2016, 8, 909. [CrossRef]

4. Jin, D.; Gu, S.; Qin, W. The growth characters and spatial distribution of urban functional area in china from 1984 to 2000. In Proceedings of the 2004 IEEE International Geoscience and Remote Sensing Symposium (IGARSS 2004), Anchorage, AK, USA, 20-24 September 2004; Volume 1072, pp. 1073-1075.

5. Sýkora, L.; Mulíček, O. The micro-regional nature of functional urban areas (fuas): Lessons from the analysis of the Czech urban and regional system. Urban Res. Pract. 2009, 2, 287-307. [CrossRef]

6. Zhao, Y.; Zhang, G.; Lin, T.; Liu, X.; Liu, J.; Lin, M.; Ye, H.; Kong, L. Towards sustainable urban communities: A composite spatial accessibility assessment for residential suitability based on network big data. Sustainability 2018, 10, 4767. [CrossRef]

7. Ma, Y.; Gopal, S. Geographically weighted regression models in estimating median home prices in towns of massachusetts based on an urban sustainability framework. Sustainability 2018, 10, 1026. [CrossRef] 
8. Zhang, X. Development characteristics and dynamic mechanism of the economic and technological development areas in China. Geogr. Res. 2002, 21, 656-666.

9. $\mathrm{Hu}, \mathrm{X}$. A study of sustainable development of China's state-level economic and technological development zones. China World Econ. 2005, 13, 92-106.

10. Zhu, L.; Zhang, J.; Sun, Y. Study on comprehensive indexes evaluation of national economic and technological development zone in China. Sci. Manag. Res. 2008, 26, 50-54.

11. Min, M.; Zhong, X. Land use in ma'anshan economic and technological development zone: Based on the land survey of typical enterprises. Asian Agric. Res. 2014, 6, 89-94.

12. Gao, C.; Jin, F. Spatial pattern and industrial characteristics of economic technological development areas in eastern coastal China. Acta Geogr. Sin. 2015, 70, 202-213.

13. Yan, W.; Guo, Q.; Li, S. A study on the division of urban economic regions based on weighted voronoi diagram. J. Cent. China Nomal Univ. 2003, 37, 567-571.

14. Farmer, C.J.Q.; Fotheringham, A.S. Network-based functional regions. Environ. Plan. A. 2011, 43, $2723-2741$. [CrossRef]

15. Wang, F.; Yuan, Z.; Chen, T. A study on the functional organization of Henan's urban system. Acta Geogr. Sin. 1992, 47, 274-283.

16. Mitchell, W.; Watts, M. Identifying functional regions in australia using hierarchical aggregation techniques. Geogr. Res. 2010, 48, 24-41. [CrossRef]

17. Wang, B.; Wu, Y.; Huang, X. Urban lang-use classfication using high resolution remote sensing data. Remote Sens. Inf. 2012, 27, 111-115.

18. Wang, C.; Wang, A.; Wang, J.; Liu, Z. Land use information extraction in the inner city of beijing based on object-oriented classification method. J. Nat. Resour. 2015, 30, 705-714.

19. Krösche, J.; Boll, S. The xpoi concept. Lect. Notes Comput. Sci. 2005, 3479, 113-119.

20. Jinag, G.; Hu, F.; Shi, L. Urban functional area identification based on call detail record data. J. Comput. Appl. 2016, 36, 2046-2050.

21. $\mathrm{Xu}, \mathrm{J} . ;$ Yang, F. A study of urban functional area identification methods based on big data of social sensing. Urban. Archit. 2017, 9, 30-34.

22. Xiang, F.; Tu, L.; Huang, B. Inferring barriers of urban city using mobile phone record. In Proceedings of the 2013 IEEE International Conference on Green Computing and Communications and IEEE Internet of Things and IEEE Cyber, Physical and Social Computing, Xi'an, China, 20-23 August 2013.

23. Liu, X.; Jiao, P.; Yuan, N.; Wang, W. Identification of multi-attribute functional urban areas under a perspective of community detection: A case study. Phys. A 2016, 462, 827-836. [CrossRef]

24. Chen, W.; Liu, L.; Liang, Y. Retail center recognition and spatial aggregating feature analysis of retail formats in guangzhou based on poi data. Geogr. Res. 2016, 35, 703-716.

25. Shi, W.; Hu, Y.; Shi, X.; Wang, Z.; Yan, H.; Xu, Z.; Ren, B.; Kuang, W.; Xu, X.; Cheng, W.; et al. Strategic transformation of regionalization for the agricultural comprehensive development: The example of Ningxia Hui autonomous region in China. J. Geogr. Sci. 2016, 26, 1675-1688. [CrossRef]

26. Qiu, M.; Du, M.; Liu, Y. Application of voronoi diagrams and multiangle measurable image in the urban poi location and site generation. In Proceedings of the IET Conference Proceedings, Institution of Engineering and Technology, 2012, Glasgow, UK, 22-25 October 2012.

27. Xiao, Y.; Chen, X.; Li, Q.; Yu, X.; Chen, J.; Guo, J. Exploring determinants of housing prices in beijing: An enhanced hedonic regression with open access poi data. Int. J. Geo-Inform. 2017, 6, 358. [CrossRef]

28. Zhu, X.; Zhou, C. POI inquiries and data update based on lbs. In Proceedings of the 2009 International Symposium on Information Engineering and Electronic Commerce, Ternopil, Ukraine, 16-17 May 2009.

29. Min, Y.; Tinghua, A.I.; Wei, L.U.; Cheng, X.; Qi, Z. A real-time generalization and multi-scale visualization method for poi data in volunteered geographic information. Acta Geod. Cartogr. Sin. 2015, 44, 228-234.

30. Zhao, W.; Li, Q.; Li, B. Extracting hierarchical landmarks from urban poi data. J. Remote Sens. 2011, 15, 973-988.

31. Zhang, X.; Du, S.; Wang, Q. Hierarchical semantic cognition for urban functional zones with vhr satellite images and poi data. ISPRS J. Photogramm. Remote Sens. 2017, 132, 170-184. [CrossRef]

32. Jiang, S.; Alves, A.; Rodrigues, F.; Ferreira, J.; Pereira, F.C. Mining point-of-interest data from social networks for urban land use classification and disaggregation. Comput. Environ. Urban Syst. 2015, 53, 36-46. [CrossRef] 
33. Pouke, M.; Goncalves, J.; Ferreira, D.; Kostakos, V. Practical simulation of virtual crowds using points of interest. Comput. Environ. Urban Syst. 2016, 57, 118-129. [CrossRef]

34. Chen, J.; Li, X.; Cheung, W.K.; Li, K. Effective successive poi recommendation inferred with individual behavior and group preference. Neurocomputing 2016, 210, 174-184. [CrossRef]

35. Xu, Z.; Gao, X. A novel method for identifying the boundary of urban built-up areas with poi data. Acta Geogr. Sin. 2016, 71, 928-939.

36. Kang, Y.; Wang, Y.; Xia, Z.; Chi, J.; Jiao, M.; Wei, Z.W. Identification and classification of wuhan urban districts based on poi. J. Geomat. 2018, 43, 81-85.

37. Chi, J.; Jiao, L.; Dong, T.; Gu, Y.; Ma, Y. Quantitative identification and visualization of urban functional area based on poi data. J. Geomat. 2016, 41, 68-73.

38. Li, G.; Jin, F.; Chen, Y.; Jiao, J.; Liu, S. Location characteristics and differentiation mechanism of logistics nodes and industry based on points of interest(poi): A case study of Beijing. Acta Geogr. Sin. 2017, 72, 1091-1103.

39. Yuan, J.; Zheng, Y.; Xie, X. Discovering regions of different functions in a city using human mobility and pois. In Proceedings of the ACM SIGKDD International Conference on Knowledge Discovery and Data Mining, 2012, Beijing, China, 12-16 August 2012.

40. Liu, Y.; Liu, X.; Gao, S.; Gong, L.; Kang, C.; Zhi, Y.; Chi, G.; Shi, L. Social sensing: A new approach to understanding our socioeconomic environments. Ann. Assoc. Am. Geogr. 2015, 105, 512-530. [CrossRef]

41. Cao, K.; Guo, H.; Zhang, Y. Comparison of approaches for urban functional zones classification based on multi-source geospatial data: A case study in Yuzhong district, Chongqing, China. Sustainability 2019, 11, 660. [CrossRef]

42. McKenzie, G.; Janowicz, K.; Gao, S.; Yang, J.-A.; Hu, Y. Poi Pulse: A Multi-Granular, Semantic Signature-Based Information Observatory for the Interactive Visualization of Big Geosocial Data. Cartograph. Int. J. Geograph. Infor. Geovisualization 2015, 50, 71-85. [CrossRef]

43. Tian, G.; Wu, J.; Yang, Z. Spatial pattern of urban functions in the beijing metropolitan region. Habitat Int. 2010, 34, 249-255. [CrossRef]

44. Cheng, X.; Shao, H.; Li, Y.; Shen, C.; Liang, P. Urban land intensive use evaluation study based on nighttime light-A case study of the Yangtze river economic belt. Sustainability 2019, 11, 675. [CrossRef]

45. Song, J.; Lin, T.; Li, X.; Prishchepov, A.V. Mapping urban functional zones by integrating very high spatial resolution remote sensing imagery and points of interest: A case study of Xiamen, China. Remote Sens. 2018, 10, 1737. [CrossRef]

46. AutoNavi. Amap Api. Available online: https://lbs.amap.com/api/webservice/guide/api/search/ (accessed on 1 November 2017).

47. Outline of the Eleventh Five-Year Plan for Economic and Social Development of National Economic and Technological Development Zones; Ministry of Commerce of the People's Republic of China, Ministry of Land and Resources of the People's Republic of China: Beijing, China, 2006.

48. Wong, S.-W.; Tang, B.-S.; van Horen, B. Strategic urban management in china: A case study of Guangzhou development district. Habitat Int. 2006, 30, 645-667. [CrossRef]

49. Li, W.; Xue, D.; Huang, X. The role of manufacturing in sustainable economic development: A case of Guangzhou, China. Sustainability 2018, 10, 3039. [CrossRef]

50. Wong, S.-W.; Tang, B.-S. Challenges to the sustainability of 'development zones': A case study of Guangzhou development district, China. Cities 2005, 22, 303-316. [CrossRef]

51. Some Opinions of the General Office of the State Council on Promoting the Reform and Innovative Development of Development Zones; Council, General Office of the State Council: Beijing, China, 2017.

(C) 2019 by the authors. Licensee MDPI, Basel, Switzerland. This article is an open access article distributed under the terms and conditions of the Creative Commons Attribution (CC BY) license (http://creativecommons.org/licenses/by/4.0/). 